Victor Faria Blanc FRCPC, Jean-Louis Jacob FRCsC, Jean Milot FrCsC, Louise Cyrenne FrCPC

\title{
The oculorespiratory reflex revisited
}

Continuous measurement of the ittratracheal pressure and capnography are very simple and accessible methods for the detection and recording of the oculorespiratory reflex (ORR). Eight heolthy children (five to 14 years old) undergoing strabismus surgery under halothane-mitrous oxide anaesthesia with spontaneous ventilation were studied. The ORR was evoked by traction on the extrinsic muscles of the eye (four medial recti and four lateral recti). Slowing of the respiratory rate andlor shallow respiratory movements were observed in each patiens. One patient developed apnoea of 20 seconds duration which forced the use of manually controlled ventilation. Intravenous atropine $\left(0.01 \mathrm{mg} \cdot \mathrm{kg}^{-1}\right)$ reduced the incidence of positive OCR (10 37.5 per cent) but did not diminish the incidence of the ORR (100 per cent). Since the ORR may lead to hypercapnia and hypoxaemia, controlled ventilation is recommended for patients undergoing strabismus surgury at least immediately before and during the muscular traction. It is now clear that the ORR may be evoked by traction on the extrinsic muscles of the eye, may produce hypercapnia and hypoxaemia and so, may aggravate the consequences of the $O C R$.

\section{Key words}

REFLEXES: oculorespiratory reflex, oculocardiac reflex; SURGERY: strabismus; ANAESTHESIA: paediatric; anticholinergic, antimuscarinic drugs; hypercapnia, hYPOXaEmIa. PARASYMPATHETIC NERVOUS SYSTEM: RESPIRATION:

From the Departments of Anaesthesia and Ophthalmology (J-LJ, JM), Hôpital Sainte-Justine and Université de Montréal, Montréal, Québec.

Address correspondence to: Victor Faria Blanc MD, Department of Anaesthesia, Hôpital Sainte-Justine, 3175 Chemin Côte Ste-Catherine, Montréal, Québec, H3T 1C5.
The oculorespiratory reflex (ORR) was first described by Aschner (1908) in the rabbit submitted to bulbar pressture.' In 1914-1915, Petzetakis described the ORR evoked by pressure on the eyes of humans. ${ }^{2,3}$

The clinical manifestations of the ORR include bradypnoea, expiratory gasp or inspiratory pauses, shallow respiratory movements and respiratory arrest. ${ }^{1-6}$

The ORR and the oculocardiac reflex (OCR) are separate but intimately associated reflexes. The afferent arc of each is identical, ${ }^{1,7-9}$ while the efferent arc is clearly different. In fact, Petzetakis reported that atropine abolishes the OCR without changing the incidence of the $\mathrm{ORR} ;{ }^{2}$ and Delava, ${ }^{5}$ like Joffe and Gay, ${ }^{10}$ reported that, in the dog, intravenous atropine enhances the ORR. These pharmacological differences observed with intravenous atropine strongly suggest that the ORR is independent of the vagus nerve

Deiava demonstrated, in the dog, that bilateral vagotomy and section of the spinal cord at the level of the seventh cervical vertebra (phrenic nerves intact) does not abolish the ORR. ${ }^{5}$ While the efferent pathway for the ORR is not clearly elucidated, it seems reasonable to postulate that the afferent impulses reaching the main sensory nucleus of the trigeminal nerve stimulate fibers which reach the pneumotaxic respiratory centre in the ventrolateral tegmentum of the pons. Signals sent from this area to the medullary respiratory area (inspiratory and expiratory centres) would result in inspiratory inhibition and/or expiratory facilitation, through the phrenic and other respiratory nerves, which lead to bradypnoea, irregular respiratory movements and, finally, to respiratory arrest.

No mention is made of the ORR in current textbooks of anaesthesia.

The following study introduces two simple methods for the detcetion and recording of the ORR. It is centred around two basic questions:

(a) Is it possible to elicit the ORR by traction on the extrinsic muscles of the eye?

(b) How important may the ORR be in patients undergoing squint correction?

\section{Methods}

Eight children (four males and four females) five to 14 years of age and ASA physical status I, requiring correction of strabismus under general anaesthesia, were studied after informed consent was obtained from the 


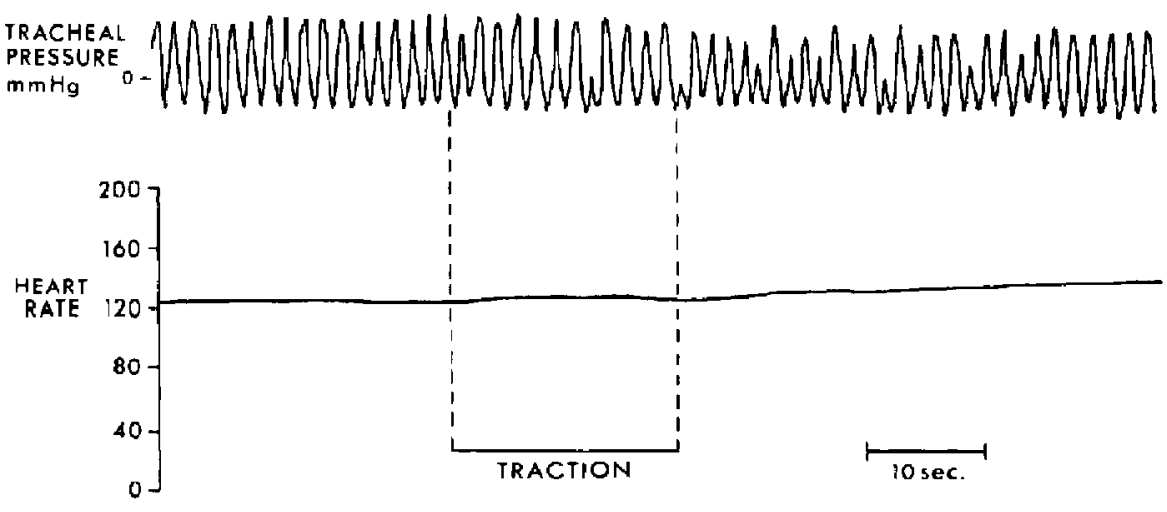

FIGURE 1 A positive ORR (slowing of the respiratory rate und shallow respiratory movements in the tracheal pressure tracing) and negative OCR (no significant change in the heart rate), during and after traction on the left lateral rectus of a five-year-old boy.

parents. The protocol for this study was approved by the Committce on Medical Ethics of the Hôpital SainteJustine. Every child had the following monitoring: precordial stethoscope, continuous ECG (CM-5), regular blood pressure measurements with a Dinamap (Vital Signs Monitor - Model 1846) and rectal thermometry. No premedication was given. Induction was achieved with halothane, nitrous oxide and oxygen ( 40 per cent) by mask. Intravenous atropine $\left(0.01 \mathrm{mg} \cdot \mathrm{kg}^{-1}\right)$ was then given. When the tachycardia was established, tracheal intubation was performed, without the use of muscle relaxants, under deep halothane-oxygen anaesthesia. After intubation, anaesthesia was maintained with halothane ( 1.5 per cent), nitrous oxide and oxygen ( 40 per cent), using a Bain circuit with a fresh gas flow not less than $260 \mathrm{ml} \cdot \mathrm{kg}^{-1}$, with spontaneous breathing, in six of the children. In the two remaining patients an Ohio circle system with carbon dioxide absorption replaced the $B$ ain circuit, in order to obtain capnographic tracings.

Incision of the conjunctiva was done nasally or temporally by a fornix approach according to the muscle to bc operated upon, with minimal mobilization of the globe in order not to elicit the ORR and/or the OCR. Secondly, a muscle hook was gently engaged under the muscle tendon. The dissection was kept minimal, thus avoiding traction on the muscle to be studied.

Using a four channel Gould recorder, we obtained a continuous and simultaneous recording of the heart rate (Gould ECG Rate Amplifier - Model 13-4615-6X), of the intratracheal pressure (P23 Gould Statham Pressure Transducer), and of the muscular traction duration (Gould Time Marker), in each patient. In two children, the expired carbon dioxide $\left(\mathrm{PeCO}_{2}\right)$ was also recorded, using an
Ohio circle system with $\mathrm{CO}_{2}$ absorption and a Siemens (Sirecust 322) capnograph. Twenty to 25 minutes after intravenous atropine and tracheal intubation, when the heart and respiratory rates were stable, a square wave stimulus of $200-250 \mathrm{~g}$, lasting $10-15$ seconds, was applied to the extraocular muscle to be studied. "

The ORR was defined as a fall in respiratory rate of ten per cent or more (in the tracheal pressure and capnographic (races) and/or the development of shallow respiratory movements (in the tracheal pressure tracing). The OCR was considered to have occurred when the heart rate slowed at least 12 beats $\cdot \mathrm{min}^{-1}(3 \mathrm{~mm}$ downwand deflection in the heart rate tracing)

\section{Results}

The extraocular traction invariably produced slowing of the respiratory rate, even when the heart rate remained stable. As soon as an extraocular muscle was stimulated the respiratory pattern changed. Inspiratory pauses, slowing of the respiratory rate and/or shallow respiratory movements, were constantly observed (Figures 1 and 2). Moreover, in the two patients studied with capnography the $\mathrm{PECO}_{2}$ raised from a mean value of $41 \mathrm{mmHg}(5.453$ $\mathrm{kPa}$ ) to a mean value of $47 \mathrm{mmHg}(6.251 \mathrm{kPa})$. Slowing of the respiratory rate, shallow respiratory movements and elevated $\mathrm{PECO}_{2}$ persisted for 35-40 seconds after releasing the muscular traction (Figures 1 and 2). In one patient (14 year old female), respiratory arrest occurred 12.5 seconds after the release of the extraocular muscle traction (right medial rectus) and forced the initiation of manually controlled ventilation, after 20 seconds of persistent apnoea (Figure 3).

No measurable variation occurred in the capnographic 

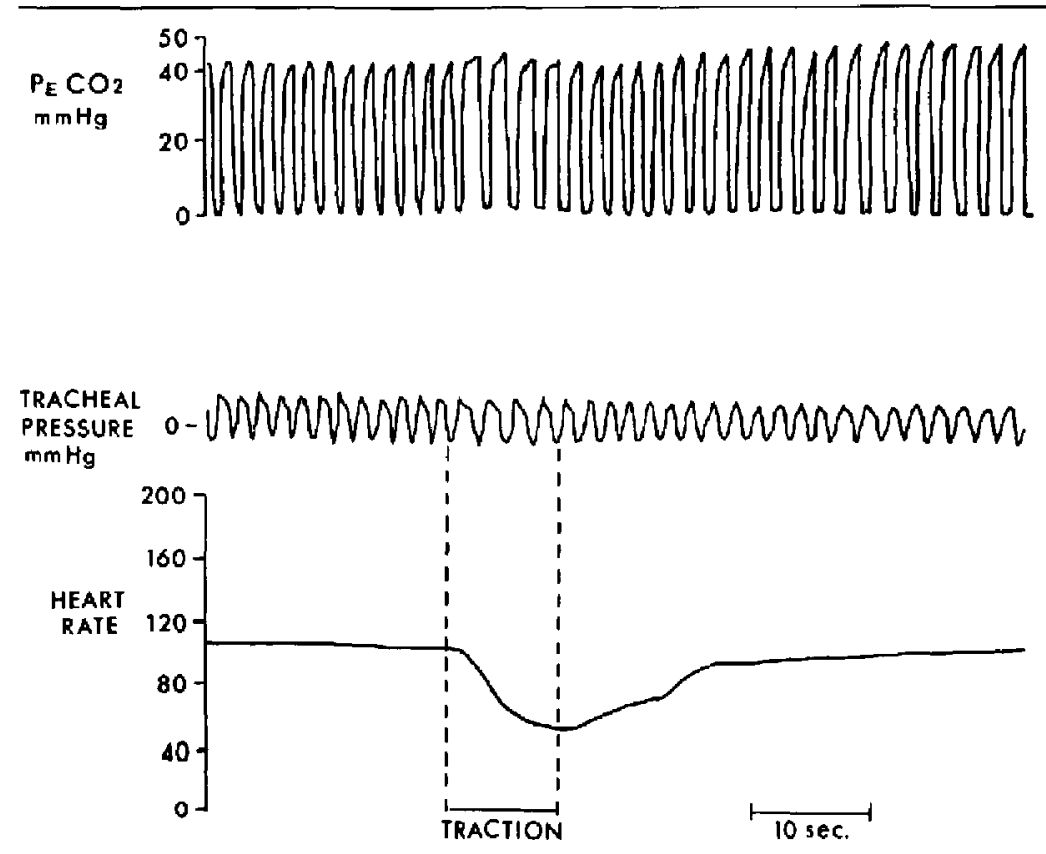

FIGURE 2 Note slowing of the respiratory rate with inspiratory pauses ( $\mathrm{PECO}_{2}$ and tracheal pressure tracings), hypercapnin (from 42 to $4 \mathrm{~B} \mathrm{mmHg}$ - $\mathrm{PECO}_{2}$ tracing) and positive OCR (bradycardia, in the heart rate tracing), as soon as the muscular traction is started. Obtained from the left medial rectus of an eight-year-old girl.

and tracheal pressure traces in the control period, while clear variations were noted during and after the muscular stimulation. This allows conclusion that the variations, including the rise in end-tidal $\mathrm{CO}_{2}$, were real and not coincidental.

Intravenous atropine $\left(0.01 \mathrm{mg} \cdot \mathrm{kg}^{-1}\right)$ prevented the OCR in 62.5 per cent of our patients but did not abolish the ORR which was evident in each case.

\section{Discussion}

The present study clearly proves that the ORR can also be evoked by extraocular muscle traction. Using highly reflexogenic stimuli (square wave tractions of $200-250 \mathrm{~g}$ lasting $10-15$ seconds), we observed 100 per cent of positive ORR versus 37.5 per cent of positive OCR, despite the fact that each patient had received intravenous atropine $\left(0.01 \mathrm{mg} \cdot \mathrm{kg}^{-1}\right) 20$ to 25 minutes before the muscular stimulation. In fact, it has been reported that atropine does not prevent the ORR elicited by pressure on the eyeballs of human beings ${ }^{2}$ and rather enhances the ORR evoked by bulbar pressure in the dog, ${ }^{5.10}$

The present study was not designed to determine the significance of the type of stimulus in the incidence of the
ORR. We used highly reflexogenic stimuli (type A or square wave stimuli) ${ }^{11}$ because we wanted to know if the ORR may be evoked by traction on the extrinsic muscles of the eye. As we know that the type of stimulus is a determinant factor in the incidence of the $O C R^{11}$ it seemed reasonable to postulate that this should be true for any other mechanically evoked reflex.

Several years of systematic clinical observation permit to conclude that surgeons not aware of the importance of the stimulus do use highly reflexogenic muscular tractions and get a high incidence of positive OCR. On the contrary, surgeons who practise very gradual and gentle manipulation of the extraocular muscles have a very low incidence of positive $\mathrm{OCR}$.

Our results show that the ORR is a frequent and potentially dangerous occurrence during strabismus surgery when highly reflexogenic stimuli are used. This reflex, not abolished by intravenous atropine, may lead to bradypnoea with hypercapnia (Figure 2) and may culminate in apnoea with consequent hypoxaemia (Figure 3 ). Although others, using very different methods, with undefined stimuli, have concluded that the use of controlled ventilation does not reduce the incidence of the 


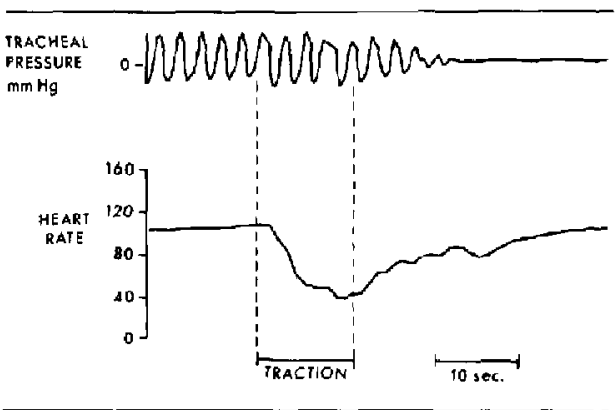

FIGURE 3 Bradypnoea and ircgular respiratory movements followed by apnoea (positive ORR - tracheal pressure tracing) and slow to recover bradycardia (positive $O C R$ - heart rate tracing), atter traction on the right medial rectus of a 14-year-old girl

OCR, ${ }^{12,13}$ we conclude that controlled ventilation must be preferted to spontaneous breathing, at least immediately before and during the muscular traction.

One additional question remains unanswered: how can we explain the scarceness of infornation concerning the ORR in anaesthesiology and in ophthalmology? Is it due to the fact that, finally, most of the patients undergoing squint correction are anaesthetized with assisted or controlled ventilation? Is it due to the "reflex of automatically bagging the patient" when something is wrong? We do not know.

As we stressed previously, " the type of stimulus being the determinant factor of the OCR, minimal, very gradual and gentle manipulation of the extraocular muscles is required to diminish the incidence or the intensity of the OCR and the occurrence of cardiac arrhythmias.

Well managed anaesthesia is equally important. Controlled ventilation must be preferred to spontaneous ventilation, at least immediately before and during the muscular traction. Hypercapnia does augment the incidence of the OCR in spontancously breathing infants and children $^{11}$ and hypoxaemia must be prevented when facing the possibility of cardiac arhythmias. These ventilatory abnormalities may be due to, or aggravated by an ORR.

Intravenous antimuscarinics effectively reduce the incidence of bradycardia and of bradyarrhythmias, during strabismus surgery and, consequently, are indicated. But we have to remember that these drugs do not abolish the ORR and so, do not eliminate the need for ventilatory control.

Perfect co-operation between the surgeon and the anaesthetist is mandatory. Both must realize the importance of the different factors causing or favouring the OCR and the ORR.

If the OCR is elicited, the surgeon must release the traction, wait for normal hcart rate, then continue the operation with gentler manipulation.

\section{Acknowledgements}

We thank all the members of the Department of Biomedical Enginecring of the Hôpital Sainte-Justine for their invaluable assistance. Also, we extend a note of appreciation to the nurses of the operating room, to the anaesthetic and inhalotherapy staff, who devotedly assisted us.

\section{References}

1 Aschner $B$. Über einen bisher noch nicht beschriebenen Reflex von Auge auf Kreislauf und Atmung: Verschinden des Radialispulses bei Druk auf das Auge. Wein Klin Wschr 1908; 1529-30.

2 Petzetakis $M$. Reflexe oculo-respiratoire et reflexe oculovaso-moteur à l'état normal. Bull Soc Méd Hôp Paris $1914 ; 37: 816-22$

3 Petzetakis $M$. Effets réflexes de la compression oculaire a l'état nonnal. Réflexes: oculo-cardiaque, oculo-respiratoire. oculo-vasomoteur. J Physiolog, Paris 1915; 16: 1027-48.

4 Salamagne JC, Le réflcxe oculo-cardiaque - L'anesthésic en Ophtalmologie - XXVII Congrès National d'Anesthésie et de Réanimation, Bordeaux, France, pp. 41-59 (1979).

5 Delava $P$. Étude des effets de la compression oculaire sur la circulation ct la respiration. Roy Belg Clin Sci 1914; 196-220.

6 Foster CS, Brennan L. The oculocardiac reflex and the oculorespiratory reflex. J Am Nurse Anesth 1974; 42: $317-22$.

7 Gay AJ, Joffe WS, Barnet $R$. The afferent course of the oculorespiratory reflex of the third, fourth and sixth cranial nerves. Invest Ophthal 1964; 3: 451-8.

8 Joffe WS, Gay AJ, Antrim CC. Trigeminal pathway for afferent fibers from the oculomotor nerves. Invest $\mathrm{Oph}$ thal 1966; 5: 222-7.

9 Pöntinen PJ. The importance of the oculocardiac reflex during ocular surgery. Acta Ophthal Suppl 1966; 86: $7-66$.

10 Jaffe WS, Gay $A J$. The oculorespiratory reflex in the dog. Invest Ophthal 1966; 5: 550-4.

11 Blanc $V F$, Hardy $J F$, Milot J, Jacab JL. The oculocardiac reflex: a graphic and statistical analysis in infants and children. Can Anaesth Soc J 1983; 30: 360-9.

12 Foresiner $\sqrt{E}$, Imbrecht $P$. Controlled respiration does not jnhibit oculocardiac reflex during strabismus surgery in children. Anesthesiology 1983; 59; A457.

13 Mirakhur RK, Shepherd WFI, Jones $C J$. Ventilation and the oculocardiac reflex. Prevention of oculocardiac reflex during surgery for squints: role of controlled ventilation and anticholinergic drugs. Anaesthesia 1986; 41 : 825-8. 


\section{Résumé}

Cette étude a été conçue afin de savoir si le réftlexe oculorespir. atoire (ROR) peut être déclenché par l'étirement des muscules exirinsèques de l'ocil at ainsi pouvoir prếsumer de son impor. rance face au réflexe oculocardiaque (ROC) Lors des corrections de strabisme. L'enregistrement graphique de la pression intratrachéale et la capnographie se sont avérées des méthodes simples et fiables pour la détection et pour l'étude du ROR. Huit enfants (de cinq d I4 ans; état physique I de la classification ASA) opérés pour des corrections de strabisme, anesthésiés d̀ l'hatothane et au protoxyde d'azote, en respiration spontcnée. fârent étudiés. Nous avons employé des tractions musculaires de 200-250 grammes durant 10-15 secondes. Malgré l"emploi d'atropine par voie intraveineuse $\left(0.01 \mathrm{mg} \cdot \mathrm{kg}^{-1}\right.$ ), le $R O R$ (bradypnée, arythmie respiratoire) a été positif dans 100 pour cent des cas, alors que le ROC n' a été positif que dans 37,5 pour cent des cas. Un enfanu (fille de 14 ans) a présenté une apnée de 20 secondes, après la stimulation de son droit interne. En conclusion, le ROR est une entité assez fréquente, lors des corrections de strabisme, pouvant amener de l'hypercapnie et de l'hypoxie et, par cortséquent, pouvant aggraver le ROC el faciliter l'apparition d'arythmies cardiaques, La ventilation contrôlée est donc à recommander lors des corrections de strabisme, au moins immédiatement avant et pendant les tractions musculaires. 